\title{
X-ray Mapping Characterisation of Materials that have a Large Dynamic Compositional Range
}

\author{
Richard Wuhrer ${ }^{1}$ and Ken Moran ${ }^{2}$ \\ 1. University of Western Sydney, Advanced Materials Characterisation Facility (AMCF), Australia. \\ 2. Moran Scientific Pty Ltd, 4850 Oallen Ford Road, Bungonia, NSW, Australia.
}

X-ray mapping (XRM) characterisation of materials, has become more popular over the last few years, mainly due to the much quicker mapping times of the silicon drift detector (SDD). The maps generated often show a large dynamic range of compositions for the material being investigated. We can confidently map over 5 orders of magnitude in concentration range. Four can easily be covered by energy dispersive spectroscopy (EDS) and the fifth usually involves wavelength dispersive spectroscopy (WDS), but the different levels are not easily displayed in the same image. Figure 1 shows a number of x-ray maps of different materials showing different concentration ranges that can be mapped. Materials are rarely homogenous and quite often have a number of different phases with varying levels of elemental composition. You need to decide which range is of importance and map accordingly. Figure 2 shows quantitative elemental x-ray maps of a white cast iron where the image information is set by slider bars indicating a particular concentration range. This concentration range may be reset to reveal yet further information as it is often important to know the distribution and subtle level changes of various elements in a material. For example, metallurgists require displaying $0.1 \%$ to $0.6 \%$ of carbon in the matrix, $0.6 \%$ to $1.3 \%$ of carbon phases around carbides and at the same time variations of carbon in the carbides from $2 \%$ to $8.7 \% \mathrm{C}$ as well as subtle changes of 1$2 \%(\mathrm{wt} \%)$ in $\mathrm{Mn}$.

The use of colour can enhance the visibility of intensity levels in a map because the human eye can distinguish many more shades of colour than shades of grey [1]. One way of doing this is to use $\mathbf{a}$ false colour, sometimes called pseudo colouring, to display different elements. Pseudo colouring is a simple method for determining elemental associations and is sometimes referred to as "Primary Colour Imaging" [1]. This technique is where three elemental maps have been assigned the colours red, green and blue. Because the colours red, green and blue form specific colours when combined on a computer graphics monitor, elemental associations are clearly shown in a single pseudo colour image. As can be seen in Figure 3, we can change the sensivity levels of the colours representing different elements, which consequently change the look of the coloured x-ray map.

One further method helpful for locating phases and showing variations [2] is through rotating the colours between elements. This often reveals further information (elemental association and other phases) in the material, such as fine precipitates, trace elements, hairline cracks and small boundary interfaces that would be otherwise missed [3].

This paper will cover characterisation of materials that have a large dynamic compositional range and the effects different sensitivity levels have on the images that are produced.

References:

[1] J. J. Friel, C. E. Lyman, Microsc. Microanal. 12, 2-15, 2006.

[2] K. Moran and R. Wuhrer, Mikrochimica Acta, Vol. 155, pp. 59-66, 2006.

[3] R. Wuhrer and K. Moran, IOP Conference Series: Materials Science and Engineering Volume 55, Issue 1, 2014. 


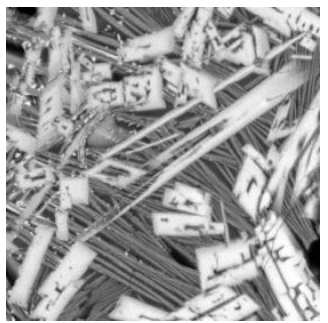

a.

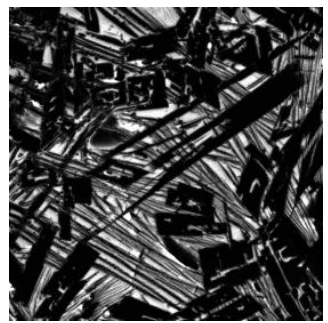

b.

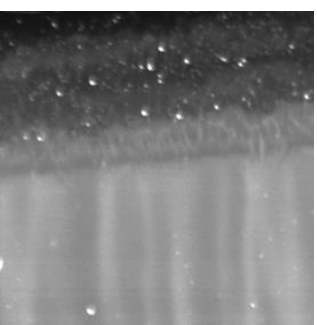

c.

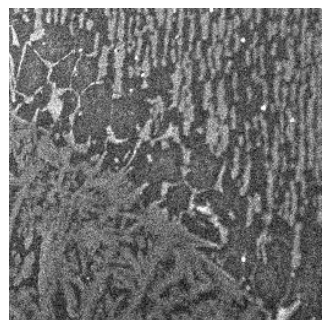

d.

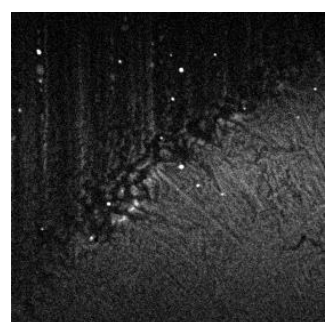

e.

Figure 1. Images with varying concentration range. a) $\mathrm{TiO}_{2}$ showing $0-100 \%$, b) $\mathrm{SiO}_{2} 0-10 \%$, c) 0 $1 \%$, d) Nitrogen $0-0.3 \%$ (WDS) and e) 0 to $150 \mathrm{ppm}$ (WDS).
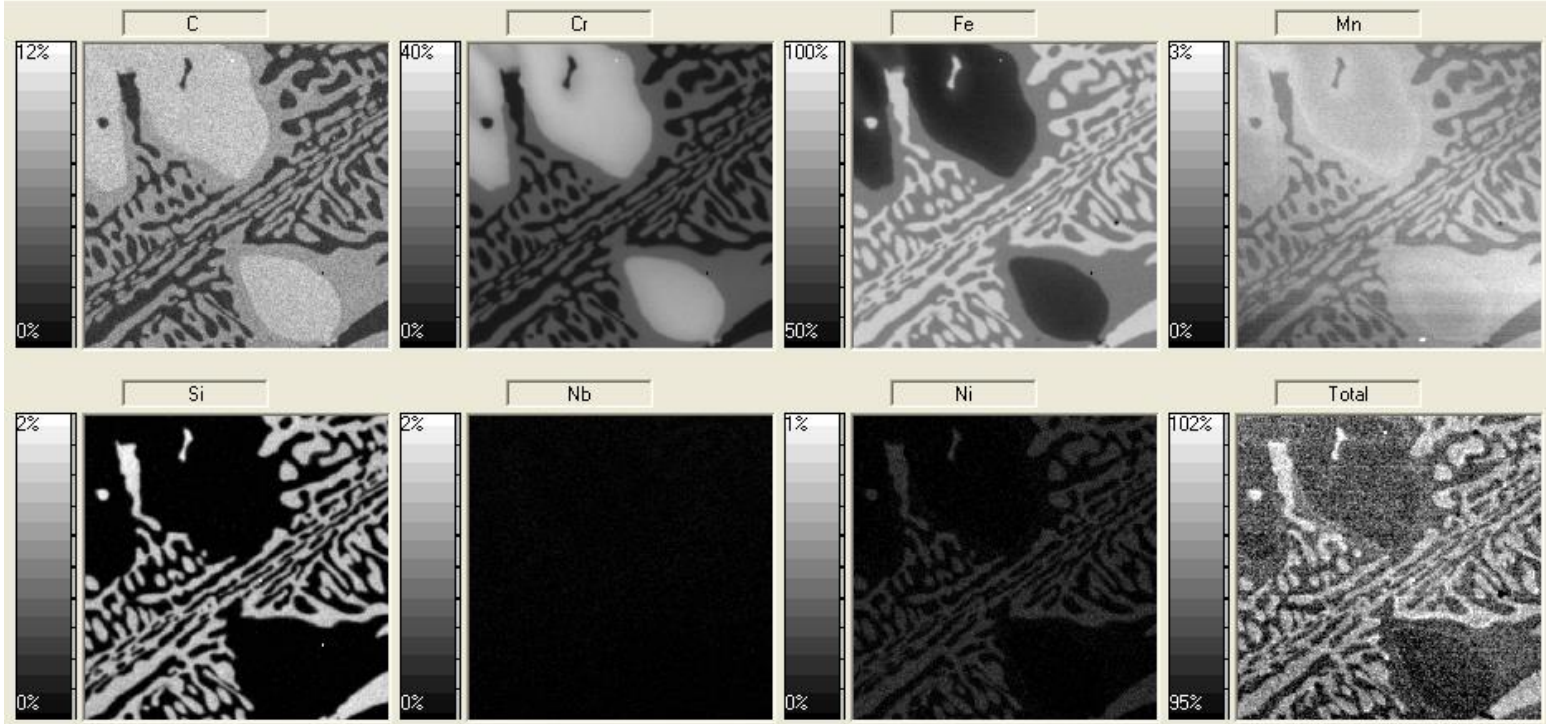

Figure 2. Quantitative X-ray maps of white cast iron sample. Vertical scales show variation in concentration levels.

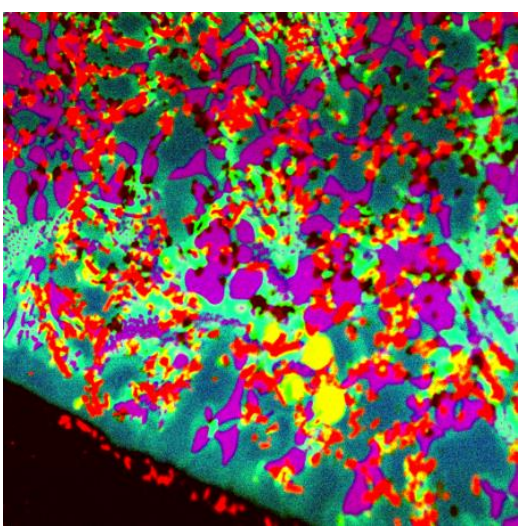

a.

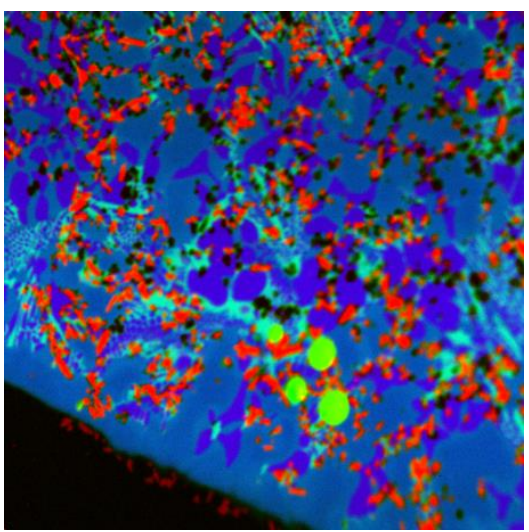

b.

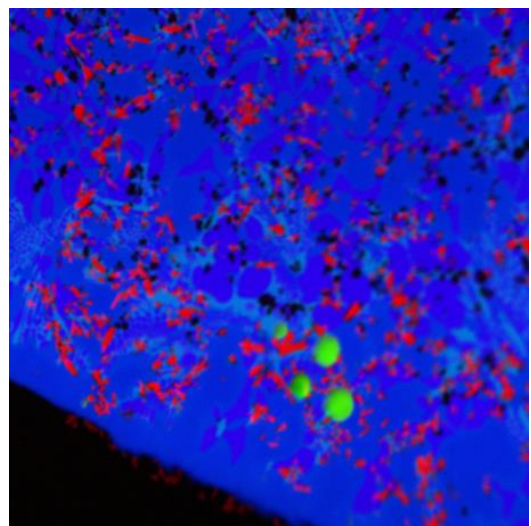

c.

Figure 3. Chrome boride nickel silicide. The dynamic range available makes it difficult to determine which makes the best image. Images a. to c. show the effect of increased sensitivity of concentration range. X-ray images $-\mathrm{HWOF}=100 \mathrm{um}, 850 \mathrm{msec} / \mathrm{pixel}, 512 \times 512$. The images a and $\mathrm{c}$ are transposed for increased sensitivity. Red=Boron, Green $=\mathrm{Si}$, Blue $=\mathrm{Ni}$ 